\title{
DOSSIÊE
}

Sociologias, Porto Alegre, ano 10, no 19, jan./jun. 2008, p. 22-39

\section{Criatividade, comunicação e produção do saber}

ARNAUD SALES

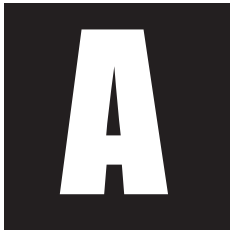

produção do saber é um dos principais elementos da dinâmica das sociedades contemporâneas, que se apóiam no saber científico e profissional em um nível sem precedentes na história humana. Os economistas ocuparam, principalmente, o campo das inovações tecnológicas, e os psicólogos dominaram por muito tempo a reflexão sobre a criatividade; os sociólogos, por sua vez, voltaram-se mais, no decorrer das últimas décadas, para a análise da produção artística e para a análise da produção do saber. Este último tema levanta inúmeras questões, algumas se revelando fundamentais para a compreensão do que origina o processo criativo. Tentaremos englobar aqui diversas facetas das relações entre criatividade, comunicação e produção do saber, temática abordada mais longamente em nossa obra recente Knowledge, Communication and Creativity (Sales e Fournier, 2007), à qual remetemos o leitor para mais detalhes. Desejamos distanciarnos, assim, da perspectiva psicológica clássica sobre a criatividade e a descoberta, por muito tempo dominante, baseando-nos essencialmente nas abordagens propostas nesta obra por Philippe Breton, Randall Collins e Rogers Hollingsworth. De fato, pode-se hoje em dia conceber a descoberta como um puro processo mental, como sendo dessocializada e fruto apenas da

\footnotetext{
* Professor titular de Sociologia da Université de Montreal e coordenador canadense do acordo de cooperação entre a UdM e o PPGS. Artigo escrito com a colaboração de Marcel Fournier e Yan Sénéchal.

1 Tradução de Patrícia Chittoni Reuillard (UFRGS), revisão técnica de A. D. Cattani
} 
"solidão" e da "iluminação" descrita por Poincaré? Como situar o papel da comunicação na elaboração das descobertas ou dos avanços intelectuais? Que papéis desempenham o indivíduo e as redes nesses avanços? Quais são, enfim, as características, sobretudo comunicacionais, das instituições mais criativas?

Tais questões não constituem elementos de debates estritamente acadêmicos. Concernem também, e muito diretamente, às práticas dos centros de pesquisa universitária, dos professores-pesquisadores e dos mestrandos e doutorandos.

\section{Criatividade, comunicação e estatuto do conhecimento}

A criatividade na produção do saber é amplamente associada ao papel poderoso da comunicação, indissoluvelmente ligada, desde a Antiguidade, à reflexão sobre a invenção. As questões associadas às relações entre esses três termos devem, segundo Philippe Breton (2007) ser correlacionadas à diversidade das formas do estatuto do conhecimento. Nesta perspectiva, deve-se partir da distinção aristotélica entre a) a ciência, que se baseia no silogismo demonstrativo a partir de premissas certas, b) o raciocínio a partir de premissas prováveis que se devem apoiar na dialética e na retórica, e enfim c) a poética, produção da ficção. Essa distinção permite pensar três tipos de conhecimentos, em função de sua pertinência relativa quanto ao recorte das zonas do real. Ela abre, na verdade, o espaço do pensamento científico, o espaço dos conhecimentos prováveis - como os da atividade política e, até certo ponto, das Ciências Humanas e Sociais (Breton, 2007: 116, 120, 122), e, por fim, o espaço da ficção.

Se excluirmos a ficção, surge uma distinção central entre o que é enunciado científico e o que é opinião. Esta é associada por Aristóteles, por um lado, ao método dialético e, por outro, à retórica. Lembremos que, no 
sentido clássico, a dialética, que se distingue do método científico, mesmo estando voltada para ele (Chrétien-Goni, 1999: 1), é um método de argumentação reservado ao debate contraditório ${ }^{2}$ para produzir conhecimentos novos, suplementares, sobre determinada opinião ${ }^{3}$. A opinião é também associada à retórica, método para convencer um auditório.

Qual é, então, o estatuto da dialética e da retórica na comunicação em relação à elaboração intelectual e, se for o caso, à descoberta? Para simplificar, pode-se dizer que, para toda idéia ou todo enunciado, quer sejam da ordem do certo ou do provável, há dois momentos, o da inventio e o da dispositio: "uma coisa é fazer que as idéias, os argumentos surjam, outra é estruturá-los de modo apropriado à sua comunicação" (ChrétienGoni, 1999: 1). A inventio vai dar um conteúdo ao discurso, ao passo que a exposição assegurará sua expressão. Isso leva então à questão - importante para os sociólogos - da representação do processo de descoberta. Com efeito, a oposição entre esses dois momentos (entre os quais existe, aliás, um intenso vaivém) levou, com muita freqüência, a associar esse processo de descoberta que, para muitos, seria, ao mesmo tempo, não socializado e incomunicável, à solidão. E, mais ainda, à busca da verdade por si, sem considerar a opinião do auditório. Isso explica principalmente por que, no século XIX, a heurística foi reduzida a uma psicologia da descoberta e leva

2 Ela não é, certamente, senão uma arte da discussão e do exame, e embora sua missão não seja a busca da verdade e seu interesse esteja voltado apenas para a opinião, para o provável, ela, ainda assim, fornece um conjunto de instrumentos "que permitem raciocinar sobre qualquer assunto" e, deste modo, acaba por mostrar-se uma espécie de metodologia geral propícia à pesquisa e "ao conhecimento dos princípios" (Chrétien-Goni, 1999: 1).

3 Para Kant, a figura da dialética é concebida como método de argumentação crítica. Ela permite "ver uma coisa em seus limites, submetê-la a uma questão de direito, fazê-la sofrer a prova da legitimidade" (Balibar, 1999: 7). A dialética, pelo debate contraditório, intervém tanto para encontrar idéias, organizá-las, quanto para colocá-las à prova, não somente no laboratório ou na solidão de um escritório, mas também diante da comunidade dos pares. Esta participa de certo modo, por meio do debate, da co-produção da descoberta pelo teste ou, mais modestamente, pela formalização da idéia, e confere a legitimidade ao enunciado ou à opinião que a estrutura. 
a pensar que os processos comunicacionais parecem intervir apenas uma vez, passado o momento solitário da inventio. Então, somente em um segundo momento (dispositio ou Method), elaborar-se-ia um discurso argumentado para dar conta da descoberta; depois, se seguirmos as seqüências das técnicas da retórica ${ }^{4}$, redigir-se-ia o que foi ordenado (elocutio ou Style) para, finalmente, defender diante de um público ou no âmbito de um debate público, o que se afirma por meio de um discurso estruturado (actio ou Delivery). Portanto, existe aqui uma posição específica que se opõe àqueles que vêem na produção, tanto dos enunciados científicos quanto de qualquer outra produção de conhecimento, uma atividade profundamente socializada.

Philippe Breton (2007: 120 e 123) contribui com um ponto importante para a discussão, salientando, em primeiro lugar, que "solidão" não quer necessariamente dizer que não haja trabalho de equipe, mas, antes, que o trabalho do cientista, ao menos na perspectiva "objetivista", orienta-se mais para a busca da "verdade" do que para uma determinada audiência, e que "a ordem da descoberta é oposta à ordem de apresentação". Somente a fase de validação da descoberta seria "socializada". Baseando-se nas diferenças de estatuto dos conhecimentos, o autor mostra, em compensação, que o procedimento do cientista solitário difere, na verdade, daquele do dialético e do retórico, daqueles que raciocinam a partir de premissas prováveis, que "trabalham" a opinião que a perspectiva objetivista tende a considerar, aliás, como um tipo de "conhecimento degradado" (Breton, 2007: 120), e que consideram desde o início a relação com o auditório: "a recepção é (então) um mecanismo essencial à própria produção". Mais ainda com os Humanistas do Renascimento, "comunicação e produção da opinião tornam-se inseparáveis", pois o conhecimento é concebido como

4 O famoso "achar o que dizer (inventio), pôr em ordem o que se achou (dispositio), redigir o que se pôs em ordem (elocutio), apresentar oralmente o que se redigiu (actio); em inglês, invention, method, style e delivery" (Douhay-Soublin, 1999: 4). 
sendo co-produzido em um debate. "O saber torna-se uma questão de rede, ao menos no que tange à opinião. Foi a partir disso que, mais tarde, muitos tentaram pensar todo conhecimento, inclusive o saber científico, como produzido no interior de redes" (Breton, 2007: 125), conforme veremos com os trabalhos de Collins. Se isso se aplica àqueles que trabalham a opinião - os pesquisadores das Ciências Humanas e Sociais -, por que, dizem os "relativistas", não se aplicaria também aos cientistas? Nesse caso, indica Breton, cuja perspectiva difere, entretanto, nesse ponto, "a produção do saber, inclusive os enunciados científicos, é vista como uma atividade eminentemente social, estando a 'verdade' dos resultados imediatamente subsumida sob sua validação social pela comunidade dos pares". Então, se levarmos a lógica da perspectiva relativista até o fim, "todo o trabalho dos cientistas consistiria na obtenção da aprovação de seus colegas, graças a dispositivos retóricos, ou até mesmo, graças a relações de poder estabelecidas a partir de pressões institucionais" (Breton, 2007, 124). Se não podemos aceitar essa perspectiva relativista, tampouco podemos aceitar a posição psicologizante. De fato, mesmo no processo de inventio que se poderia produzir no laboratório - esta "torre de marfim" dos cientistas -, não se pode abstrair, na produção contemporânea do saber, os processos comunicacionais associados ao papel dos colegas e dos pares e, mais amplamente, das redes intelectuais e científicas consideradas na próxima seção, da qualidade do meio de pesquisa em termos de trocas e debates científicos e da capacidade para transferir esquemas interpretativos a partir dessas trocas. Do mesmo modo, não se podem ignorar as enormes demandas do ambiente institucional, inclusive das empresas ou dos governos, por meio de seus programas de fomento à pesquisa. 


\section{Para além dos grandes pesquisadores, a criatividade das redes}

Em sua obra The Sociology of Philosophies. A Global Theory of Intellectual Change, Randall Collins (1998: 54) salienta que a criatividade fora do comum é particularmente rara. Ela não pode ser explicada simplesmente por meio de configurações específicas de características psicológicas, encontradas em grande número de indivíduos, ou pelas "condições gerais da sociedade circundante" ${ }^{5}$, já que essas condições afetam um grande número de pessoas. A principal condição da criatividade não é, por outro lado, a presença de indivíduos brilhantes ou geniais. O criador, o ator é a rede, isto é, o sistema de relações e de interações mais ou menos denso, conforme o caso, que funciona como uma fraternidade ou um clã. Deve-se considerar, então, a criatividade das redes intelectuais. No texto intitulado The Creativity of social Networks and the Struggle over Attention Space (2007), este autor se interessa, sobretudo, pelos intelectuais e, evidentemente, pelos filósofos. Para Collins, criatividade é mais sinônimo de definição de novos problemas, de novas temáticas, de elaboração de novos instrumentos de argumentação e, assim, de abertura de novas áreas de pesquisa para novas gerações de intelectuais (Randal Collins, 2007: 160) do que de descobertas ou de soluções para problemas.

Não se pode, por conseguinte, pensar em pensadores em esplêndido isolamento, mas em participantes de uma rede, ela própria definida como um ator no cenário intelectual. E isso deve ser pensado de modo

5 Esta última posição é, sem dúvida alguma, muito discutível, especialmente no contexto contemporâneo. De fato, pode-se imediatamente objetar, com Breton, que o estatuto da opinião e o estatuto da proposição científica não se podem afirmar senão em contextos sociais propícios. Breton avança que uma heurística da opinião só tem sentido nas sociedades democráticas abertas ao debate político, judiciário, e sobre os valores da sociedade. Isso tampouco quer dizer que todos os indivíduos nesses contextos são ao mesmo tempo formados e que se orientam para o trabalho científico ou artístico. 
intergeracional e translocal, partindo do mestre eminente, de seus discípulos e alunos também eminentes, assim como em termos de idéias, de correntes intelectuais e de energia emocional que circulam nas redes e são colocadas pelos contemporâneos no centro da atenção, sendo transmitidas de forma modificada de geração em geração: a criatividade realizando-se por conflito entre posições rivais em torno de um mesmo conjunto de problemas. Quanto ao grande pensador, canonizado pela História, não passa de uma concentração, uma destilação daquilo que a rede fez. Fica claro que Collins questiona, portanto, o papel do gênio em si na história das idéias.

A hipótese geral é a seguinte: a eminência vai para a eminência. Os intelectuais eminentes são aqueles que mantêm laços com outros intelectuais eminentes, quer esses laços sejam verticais, através das gerações, ou horizontais, com outros intelectuais em vias de se tornarem historicamente famosos. Por eminência, deve-se entender a influência que intelectuais exercem sobre as gerações futuras, como se pode ver na vasta divulgação de seus escritos e no lugar que seu nome assume na história de sua disciplina.

As redes intelectuais, indica Collins (2007: 158), são caracterizadas pela densidade, mas não aquela do clã tribal, do clube ou da cidadezinha, que leva mormente ao conformismo. O que as caracteriza é a circulação e a reordenação das idéias, a intensidade das discussões, mas também a energia emotiva e a força das ambições e das rivalidades. Por isso, os grandes pensadores são aqueles que recebem a retribuição do que acontece na rede. Essas relações, indissociavelmente cognitivas e emotivas, são, com freqüência, de tal intensidade que se pode falar de "efervescência coletiva" em torno dos grandes pensadores. Por seu grau de concentração, pela energia despendida na produção intelectual, pela inteira devoção a seu trabalho, eles exercem um poder carismático. Para os alunos, trata-se da aquisição da sofisticação intelectual, mas também da energia emocional de seus mestres. Mas isso nos reconduz à importância da solidão na produção intelectual alternando com os contatos sociais. O que leva ao ápice do 
espaço de atenção, acima da massa dos outros intelectuais, é a imensa energia emocional e a longa e intensa reflexão que conduzem a uma reordenação maior das idéias. Por um outro caminho, Collins, embora de início rejeite uma caracterização psicossocial própria à criatividade, converge sob certos aspectos, como se verá mais adiante, para Hollingsworth com sua noção de "alta complexidade cognitiva", salientando a absorção do pensador nas "conversas internalizadas da rede" e o fato de que "a criatividade é um processo que realiza coalizões em um espírito, instalando argumentos que parecem coroados de sucesso" (Collins, 2007: 164). Entretanto, para ele, todo processo de criatividade intelectual tem um caráter coletivo: é sempre a rede a portadora da ação, mesmo que a idéia esteja, em determinado instante, na mente de uma pessoa que, por outro lado, consegue formulá-la ${ }^{6}$.

É então que dialética e retórica entram em jogo nas redes, transmitindo as idéias, distribuindo-as, combatendo-as e transformando-as. Collins insiste sobre o caráter conflituoso da vida intelectual: quando não há conflito, não há criatividade, somente tradição! O que distingue aquele que chega ao apogeu dos outros reside, antes de tudo, em seu alto nível de concentração, sua energia emocional, sua "concentração fanática" (página). A própria rede gera oposições, rivalidades, que suscitam, por sua vez, a atenção para os problemas que a preocupam. A criatividade, diz Collins, articula-se à escalada da energia, ligada principalmente a uma recepção favorável no espaço de atenção.

6 É interessante observar que se trata de uma opinião adotada por certas pesquisas psicológicas. A esse respeito, os trabalhos de Mihaly Csikszentmihalyi são altamente significativos: 'My goal in this chapter will be to argue that while the mind has quite a lot to do with genius and creativity it is not the place where these phenomena can be found. The location of genius is not in any particular individual's mind, but in a virtual space, or system, where an individual interacts with a cultural domain and with a social field. It is only in the relation of these three separate entities that creativity, or the work of genius, manifests itself.' (1998: 39; ver também, 1996). 


\section{Pesquisadores e instituições: complexidade, diversidade, multidisciplinaridade e comunicação}

De modo geral, para Roger Hollingsworth (2000 e 2007), as chances de se fazerem descobertas cientificas maiores estão associadas a indivíduos caracterizados pela internalização de múltiplas culturas e pela capacidade de integrar os conhecimentos de vários campos científicos, e apoiados por instituições de pesquisa que favorecem a multidisciplinaridade e a intensidade das trocas científicas.

Interessando-se pelas características das instituições científicas mais produtivas no plano das descobertas, assim como pelos atributos gerais próprios aos pesquisadores científicos mais criativos, Rogers Hollingsworth (2000 e 2007), que concentrou suas pesquisas nas instituições e nos cientistas que fizeram as descobertas biomédicas mais importantes, leva-nos, como Colllins, ao coração da criatividade científica. Sua pesquisa toma como ponto de partida mais de 290 descobertas maiores realizadas na área das Ciências Biomédicas Fundamentais, na França, Inglaterra, Alemanha e Estados Unidos, e leva em consideração tanto as propriedades institucionais e organizacionais dos laboratórios quanto as características pessoais dos pesquisadores como, por exemplo, sua origem sociocultural e a diversidade de seus campos de interesse não científicos, seu hobby.

\subsection{O papel da alta complexidade cognitiva}

No cerne de seu estudo sobre os pesquisadores, encontra-se a noção de "high cognitive complexity", que remete à capacidade de compreender um mundo complexo, de estabelecer a "conectividade entre fenômenos em múltiplos campos científicos" e também de transpor idéias de uma área de conhecimento a outra, uma forma de "pensamento paradoxal" (paradoxical thinking). E, se a interiorização de um "alto nível de complexidade cognitiva" por um cientista é a condição necessária para fazer uma 
grande descoberta, importa compreender a variação dos altos níveis de complexidade cognitiva entre cientistas.

A análise de Hollingsworth baseia-se em fontes múltiplas: entrevistas com inúmeros cientistas de países diferentes, levantamento de arquivos e de documentos diversos (autobiografias, etc.). A hipótese que ele quer verificar é a seguinte: a complexidade cognitiva encontra suas raízes em processos psicológicos variados. Os dois processos que chamam sua atenção são a interiorização de culturas múltiplas e a existência de um hobby não científico, como o fato de dominar um instrumento de música, escrever poemas ou romances, etc.

A "identidade cultural múltipla" fornece, segundo Hollingsworth, a capacidade de viver intuitivamente em "vários mundos simultaneamente" e de "observar o mundo em termos mais complexos", daí um maior potencial de inovação. O exemplo dado aqui, certamente clássico, é o dos judeus alemães, cujos êxitos são excepcionais, o que não se explica somente pela importância dada ao livro e à aprendizagem formal nas famílias judias. "A dupla identidade interna/externa e também a marginalidade ou o status de estrangeiro", salientados igualmente por Csikszentmihalyi e Csikszentmihalyi (1993), desempenham um grande papel, como se pode ver com alguns dos ganhadores do Prêmio Nobel, tais como Gertrude Elion e Rosalyn Yalow. Conhece-se também o caso de Peter Medawar, nascido no Brasil de pai libanês e de mãe inglesa. Jovem secundarista,foi matriculado em uma das maiores "public school" da Grã-Bretanha, o Malborough College, indo em seguida para o Magdalen College de Oxford. "Medawar indeed internalized an amazing amount of cultural diversity and this proved to be an enormous asset to him as he became a boundary crosser in various scientific fields" (Hollingsworth, (2007: 139). Lembremos que ele trabalhou sobre o modo como o sistema imunológico rejeita ou aceita os transplantes de tecido humano, tendo recebido, em 1960, o Prêmio Nobel de Fisiologia e de Medicina juntamente com Sir Franck MacFarlane Burnet. 
Diversidade das origens e pluralidade dos percursos, sem dúvida, marginalidade por vezes, mas também determinação baseada no sacrifício, na disciplina e em uma grande curiosidade pelas coisas novas: eis as condições, no plano psicossocial, da inovação em ciência. Por outro lado, a diversidade não é somente religiosa ou étnica, ela também pode estar ligada à origem social.

A segunda dimensão relativa ao conceito de "high cognitive complexity" tange àquela dos passatempos não científicos (avocation)". A hipótese de Hollingsworth é de que, no caso dos cientistas, o fato de se envolverem com interesses e práticas de outras áreas e dominá-las muito bem - arte, artesanato, música, literatura, passatempos - permitem avançar na complexidade cognitiva e também terem intuições que derivam do campo não cientifico. Assim, as grandes descobertas dever-se-iam, em parte, à capacidade de estabelecer laços inesperados entre diferentes áreas.

A dimensão institucional, definida por uma liderança adequada, permite combinar os traços pessoais de cientistas dotados de alto nível de complexidade cognitiva e fazê-los trabalharem juntos em centros e laboratórios que facilitam a diversidade, a comunicação, a interação, para compreenderem fenômenos particularmente complexos... Eles poderão então, graças à sua capacidade, tanto dialética quanto retórica, traduzir seus avanços científicos para comunicá-los à comunidade cientifica, que reconhecerá, se for o caso, que se trata de uma grande descoberta.

\subsection{Quadro institucional, comunicação e multidisciplinaridade}

A criatividade reflexiva societal pode ser definida como a capacidade de uma sociedade para criar criatividade (Touraine, 1989: 10; Adhikari e Sales, 2001; Sales, Fournier e Sénéchal, 2007) por meio de sistemas de educação secularizados e sofisticados (Gellner, 1983/1989) e pela institucionalização da pesquisa científica (BenDavid, 1991/1997). Sabe-se que a implantação das configurações institucionais contemporâneas, consa- 
gradas ao fortalecimento dos processos de inovação, implica o estabelecimento em rede, o fortalecimento da coordenação e das interações, considerados como elementos centrais da produtividade cientifica. A multidisciplinaridade e a hibridação de campos científicos (Latour, 1987; Dogan, 1990 e 2000; Hollingsworth, 2000), a cooperação interorganizacional e as alianças tecnológicas estratégicas, o estabelecimento em rede tecnoeconômica em torno de nodos científicos, técnicos e de mercado (Callon, 1991, 1992) modelam fortemente essas configurações. Embora do ponto de vista das políticas nacionais de inovação esse tipo de preparação institucional revele-se necessário, seria ele suficiente? Isso está longe de ser certo, pois "se algumas instituições de pesquisa fazem descobertas maiores, a maioria não o faz" ${ }^{\prime \prime}$. Convém, portanto, considerar também as características dos centros de pesquisa.

No que diz respeito às características organizacionais dos laboratórios, Hollingsworth distingue dois tipos de laboratórios: os de tipo A, com maior "diversidade científica no plano cognitivo", e os de tipo B, que instauram campos de pesquisa mais estreitos e cuja natureza é essencialmente disciplinar. Sua conclusão é clara: a probabilidade de que uma descoberta seja feita em um laboratório de tipo A é muito maior do que em um laboratório de tipo B. Mesmo que se trate apenas de uma condição necessária, é surpreendente constatar, contudo, que é essencial integrar uma diversidade científica significativa para endereçar problemas pertinentes a diferentes campos científicos. Hollingsworth mostra, principalmente, a importância da multidisciplinaridade, o papel central da comunicação e das discussões científicas nas instituições de pesquisa para fortalecer a integração dos conhecimentos e estender os horizontes intelectuais. A diversidade e, o que é mais importante ainda, sua integração, estão intimamente relacionadas à

7 Retomada do título de uma conferência de R. Holllingsworth, "Why Some Research Organizations Make Major Discoveries, But Most Make None," Université de Montréal, Faculté des études supérieures, Janeiro de 1996. 
qualidade comunicacional desse quadro institucional e à intensa interação não somente entre os pesquisadores de um mesmo laboratório, mas também entre os laboratórios da instituição, seja por meio de conferências semanais a que cada membro se obriga a assistir, seja por meio de almoços caracterizados por discussões científicas muito animadas, de tal modo que todos possam aprender uns com os outros (Hollingsworth and Hollingsworth, 2000). Outras características organizacionais são também evidenciadas, tais como a qualidade da liderança científica articulada a uma vasta rede e a capacidade de recrutar pesquisadores de primeiro nível.

O estudo de Hollingsworth permanece, como ele mesmo lembra na conclusão, "essentially at the stage of hypothesis and/or theory generation". Pode-se privilegiar um ou outro tipo de laboratório, um ou outro tipo de organização, mas importa reconhecer que, sendo raras as grandes descobertas, é difícil planificá-las: tudo parece caótico, e há lugar para o acaso, a contingência, a sorte.

O esforço de criatividade reflexiva, próprio à operacionalização de políticas da ciência e da tecnologia não pode, por isso, ser pensado de modo determinista e independentemente da interação permanente entre os indivíduos e as instituições. As grandes descobertas devem-se a indivíduos dotados de traços notáveis e integrados a redes, mas hoje não se pode abstrair, como a pesquisa de Hollingsworth sugere, o papel considerável "de ambientes estruturais e culturais onde o potencial científico do pesquisador pode realizar-se" (2007: 149), ambientes marcados pela multidisciplinaridade e pela intensidade da comunicação entre os pesquisadores.

\section{Conclusão}

As perspectivas sociológicas aqui apresentadas certamente permitem o distanciamento de uma heurística reduzida a uma psicologia da descoberta e da criatividade. Elas ponderam o papel dos indivíduos, das redes inte- 
lectuais e científicas, da comunidade dos pares e das instituições. Seria ilusório pensar a criatividade intelectual e científica na pura solidão e na genialidade individual dos atores. Ao mesmo tempo, a compreensão da criatividade não pode abstrair o fato de que "O ator jamais é apenas social: ele não está na sociedade, mas diante dela e, sobretudo diante do poder que se oculta em suas instituições, em suas normas e interesses..." (Touraine, 1999: VI). A solidão e a iluminação, tão freqüentemente mencionadas nos relatos dos momentos de alta criatividade, não podem ser reconhecidas de outro modo. Mas, embora a complexidade cognitiva associada por Hollingsworth às grandes descobertas construa-se como habitus entre indivíduos e se torne uma de suas características e de suas forças, ela não deixa de ser forjada por experiências sociais e intelectuais marcantes. A ênfase dada por Collins ao papel das redes tende, aparentemente, a reduzir a importância dos grandes pensadores e da genialidade, em proveito do verdadeiro ator, que seria a rede. Esta não é, entretanto, uma mera estrutura de relação e de trocas. A circulação das idéias, as conversas, os debates e os conflitos que estes engendram, mobilizam indivíduos; alguns deles, talvez graças à complexidade cognitiva que os caracteriza, conseguirão fazer rearranjos criativos fundamentais que os levarão ao topo da eminência. As interações não se produzem somente in situ, mas também no pensamento, na cultura e nas práticas dos indivíduos e dos pares.

A idéia de criatividade reflexiva, própria das nossas sociedades, não pode ser pensada de maneira determinista e independentemente da interação permanente dos indivíduos em redes e instituições. As grandes infra-estruturas implantadas no âmbito de políticas da pesquisa são, sem dúvida alguma, muito úteis, senão indispensáveis, mas só podem levar a descobertas, inovações ou à definição de novas problemáticas, se as comunicações entre os pesquisadores de diferentes disciplinas se estabelecem com regularidade, liberdade e densidade. Localmente e, como sempre, internacionalmente. 


\section{Referências}

ADHIKARI, K. and SALES, A. (eds.). New Directions in the Study of Knowledge, Economy and Society, Sage Studies. In International Sociology, Monograph 2. Current Sociology, 49(4), 2001

AMABLE, B., BARRÉ, R. and BOYER, R. Les systèmes d'innovation à l'ère de la globalisation. Paris: Économica, 1997

BALIBAR, Étienne. Dialectique. In Encyclopedia Universalis sur CD-Rom, Version 5, Paris, Encyclopedia Universalis, 1999

BENDAVID, J. Éléments d'une sociologie historique des sciences. Edited with an Introduction by G. Freudenthal. Paris: Presses Universitaires de France, 1991/1997

BRETON, Philippe. Between Science and Rhetoric: a recurrent debate on the role of communication and creativity in the definition of knowledge. In A. SALES and M. FOURNIER, Eds., (2007). Knowledge, Communication and Creativity. Sage Studies in International Sociology, 56. London: SAGE, 2007

CALLON, M. Réseaux technico-économiques et irréversibilités, In R. Boyer, CHAVANCE, B. and GODARD, O. (eds), Figures de l'irréversibilité en économie. Paris: Éditions de I'Ecole des Hautes Etudes en Sciences Sociales, 1991. pp. 195-230

CALLON, M. Variété et irréversibilité dans les réseaux de conception et d'adoption des techniques. In D. Foray and C. Freeman (eds), Technologie et richesse des nations. Paris: Economica, 1992. pp. 275-324.

Centre for Educational Research and Innovation/OECD (2000) Knowledge Management in the Learning Society. Paris: OECD.

CHRÉTIEN-GONI, J.-P. Heuristique. In Encyclopaedia Universalis. Vol. 11. Paris: Édition Encyclopaedia Universalis, 2002. pp. 291-96.

COLLINS, R. The Sociology of Philosophies: a global theory of intellectual change. Cambridge: Harvard University Press, 1998

.COLLINS, R. The Creativity of Intellectual Networks and the Struggle over Attention Space. In A. Sales and M. Fournier, Eds., (2007). Knowledge, Communication and Creativity. Sage Studies in International Sociology, 56. London: SAGE, 2007. 
Csikszentmihalyi, M. and Csikszentmihalyi I.S. (1993) «Family influences on the development of Giftedness »in The Origins and Development of High Ability. Chichester Wiley (Ciba Foundation Symposium 178). (pp. 18-206).

CSIKSZENTMIHALYI, M. Creativity: Flow and the Psychology of Discovery and Invention. New York: Harper Collins, 1996.

CSIKSZENTMIHALYI, M. Creativity and Genius: A Systems Perspective. In A. Steptoe (ed.), Genius and the Mind: studies of creativity and temperament. Oxford: Oxford University Press. 1998. pp. 39-64.

CSIKSZENTMIHALYI, M. (2006) A Systems Perspective on Creativity at www.sagepub.com/upm-data/11443_01_Henry_Ch01.pdf

DOGAN, M. The Moving Frontiers of the Social Sciences. In S. R. Quah and A. Sales (eds.) The International Handbook of Sociology. London: Sage Publications, 2000 pp. 35-49.

DOGAN, M. and PAHRE, R. Creative Marginality: Innovation at the Intersections of Social Sciences. Boulder, CO: Wetview Press, 1990.

DOUHAY-SOUBLIN, F. Rhétorique. Encyclopaedia Universalis. Vol. 19. Paris: Édition Encyclopaedia Universalis, (2002) pp. 927-31.

FREEMAN, C. The National System of Innovation. In Historical Perspective, Cambridge Journal of Economics, 19(1): 1995. p. 5-24.

FREUDENTHAL, G. Introduction. In J. Ben-David, Éléments d'une sociologie historique des sciences. Paris: Presses Universitaires de France, 1991/1997. pp. 99-101.

GELLNER, E. (1983) Nations and Nationalism. Ithaca, NY: Cornell University Press. ou Gellner, E., Nations et Nationalisme, Paris, Payot, 1989.

GIBBONS, M., LIMOGES, C., NOWOTNY, H., SCHWARTZMAN, S., SCOTT, P. and Trow, M. (1994) The New Production of Knowledge: The Dynamics of Science and Research in Contemporary Societies. London: Sage.

HOLLINGSWORTH, R. and HOLLINGSWORTH, E. J. Major Discoveries and Biomedical Research Organizations: Perspectives on Interdisciplinarity, Nurturing Leadership, and Integrated Structure and Cultures', in P. Weingart and N. Stehr (eds), Practising Interdisciplinarity. Toronto: University of Toronto Press, 2000. pp. $215-44$. 
HOLLINGSWORTH, R. High Cognitive Complexity and the Making of Major Scientific Discoveries. In A. Sales and M. Fournier, Eds., (2007). Knowledge, Communication and Creativity. Sage Studies in International Sociology, 56. London: SAGE, 2007.

JOAS, H. The Creativity of Action. Chicago: The University of Chicago Press, 1992/1996.

KNORR-CETINA, K. D. Epistemic Cultures: How the Sciences Make Knowledge. Cambridge, MA: Harvard University Press, 1992/1996

LATOUR, B. and WOOLGAR, S. Laboratory Life: The Social Construction of Scientific Facts. Los Angeles, CA/London, UK: Sage, 1979.

SALES, A. and FOURNIER, M., Eds. Knowledge, Communication and Creativity. Sage Studies in International Sociology, 56. London: SAGE, 2007.

TOURAINE, A. La société post-industrielle. Paris: Denöel, 1969.

TOURAINE, A. Préface. In H. Joas, La créativité de I'agir. Paris: Cerf, 1999. pp. I—VII. 


\section{Resumo}

A produção do conhecimento é um dos elementos fundamentais da dinâmica das sociedades contemporâneas que se apóiam sobre o saber científico e profissional em níveis desiguais até agora. Este texto visa apreender, de um ponto de vista sociológico, diversas facetas da relação entre criatividade, comunicação e produção do conhecimento a partir das seguintes questões: Como situar o papel da comunicação da elaboração de descobertas ou nos avanços intelectuais? Quais são os papéis do indivíduo e das redes nesses avanços? Quais são, enfim, os traços especialmente comunicacionais das instituições mais criativas? O texto está apoiado nos trabalhos de Philippe Bretton (comunicação e estatuto do conhecimento), Randal Collins (criatividade das redes), Rogers Hollingsworth (complexidade cognitiva, diversidade instutucional, qualidade dos ambientes de pesquisa em termos de trocas e de debates científicos). Estas questões não compõe um debate estritamente acadêmico. Elas concernem também diretamente as praticas dos ambientes de pesquisa, dos professores-pesquisadores e dos estudantes de mestrado e de doutorado.

Palavras-chave: criatividade, produção saber, comunicação.

Recebido:15/12/2007

Aceite final: 06/022008 


\section{Creativity, communication and knowledge production}

\section{Arnaud Sales}

Knowledge production is a key element of the dynamics of contemporary societies that until now have been based on uneven levels of scientific and professional knowledge. The aim of this work is to understand, from a sociological point of view, the various aspects of the relationship between creativity, communication and knowledge production, starting from the following questions: What is the role of communication in the elaboration of discoveries or intellectual advances? What is the role of individuals and networks in these advances? And finally, what are the characteristics, especially the communicational ones, of the more creative institutions? The text is based on the works of Philippe Breton (communication and the status of knowledge), Randal Collins (network creativity), Rogers Hollingsworth (cognitive complexity, institutional diversity, quality of the research environment in terms of scientific exchange and discussion). These questions are not restricted to a strictly academic debate. They are also directly related to the practices of research environments, professors-researchers and students of master's and doctor's degree.

Keywords: creativity, communication, knowledge production, discovery, networks, cognitive complexity, quality of the research environment. 